\title{
KOMPARATYSTYKA METOD SZACOWANIA KOSZTÓW WYTWARZANIA ENERGII ELEKTRYCZNEJ
}

\author{
Wioletta Skrodzka \\ Politechnika Częstochowska \\ Wydział Zarządzania
}

\begin{abstract}
Streszczenie: Metodyka analizy kosztów wytwarzania energii elektrycznej powinna uwzględniać cały okres życia elektrowni, obejmujący czas budowy i eksploatacji oraz ewentualne koszty związane z likwidacją obiektu. Koszty powinny obejmować całość poniesionych nakładów inwestycyjnych i kosztów eksploatacyjnych wraz z kosztami oddziaływania na środowisko. Ich wartości należy sprowadzić do wspólnego momentu czasowego z uwzględnieniem rachunku dyskonta. Celem artykułu jest analiza porównawcza, ustalenie zależności, pokrewieństw, analogii pomiędzy metodologią szacowania kosztów wytwarzania energii elektrycznej stosowaną w Unii Europejskiej i USA.
\end{abstract}

Słowa kluczowe: energia elektryczna, koszty wytwarzania, jednostkowe, zdyskontowane koszty wytwarzania energii elektrycznej

DOI: 10.17512/znpcz.2017.4.1.09

\section{Wprowadzenie}

Zachodzące zmiany technologiczne na rynku energii, jak również zmiany geopolityczne przyczyniły się w ostatnich latach do spadku cen surowców energetycznych, zwłaszcza ropy naftowej. W Europie, która jest jednym z głównych importerów energii, skutkowało to ożywieniem gospodarki. Jednak niższe ceny nie mogą odwrócić uwag od podstawowych problemów energetycznych, przed którymi stoi świat: bezpieczeństwa energetycznego, konkurencyjności i zmian klimatycznych. Dane i analizy prezentowane $\mathrm{w}$ ostatnim sprawozdaniu Komisji Europejskiej z 30 listopada 2016 r. (EU Commission 2016) pokazują, jak gwałtownie może zmieniać się podaż i popyt na energię elektryczną, wyznaczają ścieżki rozwoju unii energetycznej w zmieniającym się krajobrazie energetycznym. Podkreślają również, że efektywne wykorzystanie zasobów energetycznych ma kluczowe znaczenie dla wzrostu gospodarczego i zrównoważonego rozwoju społecznego. Światowa Komisja ds. Środowiska i Rozwoju (WCED - World Commission on Environment and Development) definiuje koncepcję zrównoważonego rozwoju, podkreślając znaczenie długoterminowej produktywności dostępnych zasobów w świetle poprawy dobrostanu i dobrobytu człowieka (WCED Brundtland Commission 1987). Koncepcja zrównoważonego rozwoju w odniesieniu do sektora elektroenergetycznego prowadzi do dogłębnego oszacowania poszczególnych opcji wytwarzania energii elektrycznej z uwzględnieniem możliwości absorpcyjnych środowiska oraz ograniczeniem negatywnych skutków ekologicznych i zmian klimatu. Porównując i oceniając 
technologie energetyczne oraz łańcuchy dostaw energii, zauważyć można, że oszacowane koszty muszą być oparte na porównywalnych miarach uwzględniających łączne zużycie zasobów, zagrożenie dla środowiska i zdrowia ludzkiego. Niestety, powszechnie stosowane miary nie spełniają tych postulatów. Odpowiednią miarą byłby całkowity koszt społeczny przypadający na jednostkę energii elektrycznej. Społeczny koszt energii (social opportunity cost) obejmujący całość nakładów i kosztów ponoszonych przez społeczeństwo, związanych ze zużyciem i przetworzeniem zasobów energetycznych oraz z wystąpieniem niekorzystnych zmian środowiska i pogorszeniem bytu obywateli odzwierciedlałby rzeczywisty koszt produkcji energii elektrycznej, obejmując zarówno koszty ponoszone bezpośrednio, jak i koszty zewnętrzne pojawiające się w całym łańcuchu przemian energetycznych. Tego typu oszacowanie powinno być przeprowadzone dla pełnego cyklu technologicznego (Life Cycle Assessment - LCA), obejmującego poszukiwanie zasobów, wydobycie, przetwarzanie paliwa, transport, przetwarzanie i składowanie odpadów, koszty oddziaływania na środowisko (Li i in. 2017, s. 1899-1911). Powinno uwzględniać koszty związane z uruchomieniem infrastruktury, zapotrzebowanie na energię w procesach wstępnych i finalnych. Właściwa, szczegółowa ocena wszystkich etapów w cyklu paliwowym warunkuje prawidłowe porównanie opcji wytwarzania energii elektrycznej z uwzględ-nieniem warunków zrównoważonego rozwoju. Podstawą wyboru nośnika energii pierwotnej powinna być zatem również ocena społecznego kosztu jego pozyskania i przetwarzania (np. spalanie lub proces łańcuchowej reakcji rozszczepienia) z uwzględnieniem wszystkich konsekwencji. Należy jednak stwierdzić, że znajomość społecznych kosztów energii elektrycznej nie zawsze jest uwzględniana przy ocenie efektywności inwestycji elektroenergetycznych.

Celem artykułu jest analiza porównawcza, ustalenie zależności, pokrewieństw, analogii pomiędzy metodologią szacowania kosztów wytwarzania energii elektrycznej stosowaną w Unii Europejskiej i USA.

\section{Metodologia wyznaczania jednostkowego kosztu energii elektrycznej}

Literatura przedmiotu prezentuje wiele metod wyznaczania jednostkowego kosztu wytwarzania energii elektrycznej, różniących się stosowaną metodyką, założeniami oraz przyjętymi w obliczeniach wartościami parametrów (Paska 2012, s. 24-28). Większość z nich oparta jest na modelach dyskontowych. Niestety najczęściej nie uwzględniają one w pełni tzw. kosztów zewnętrznych, związanych z emisją gazów cieplarnianych, niekorzystnymi skutkami zdrowotnymi emisji zanieczyszczeń, spadkiem bioróżnorodności, utratą plonów, niszczeniem elewacji budynków czy też korozją materiałów.

\section{Metoda UNIPEDE}

Powszechnie stosowaną jest metoda UNIPEDE, zaproponowana przez Międzynarodową Unię Producentów i Dystrybutorów Energii Elektrycznej (UNIPEDE International Union of Producers \& Distributors of Electrical), opracowana pod koniec lat 70., a następnie przyjęta w krajach Unii Europejskiej (Frydrychowicz- 
-Jastrzębska, Bugała 2014, s. 68-71). Zdyskontowany jednostkowy koszt wytwarzania energii elektrycznej wyrażony jest następującym wzorem:

$$
k_{j}=\frac{\sum_{t=b+1}^{0} \frac{I_{t}}{(1+d)^{t}}+\sum_{t=1}^{N} \frac{K U_{t}+A_{t} \cdot k_{p t}}{(1+d)^{t}}}{\sum_{t=1}^{N} \frac{P_{t} \cdot T_{t}}{(1+d)^{t}}}
$$

W przypadku gdy czas budowy obiektu nie przekracza jednego roku, postać wzoru jest następująca:

Gdzie:

$$
k_{j}=\frac{I_{0}+\sum_{t=1}^{N} \frac{K U_{t}+A_{t} \cdot k_{p t}}{(1+d)^{t}}}{\sum_{t=1}^{N} \frac{P_{t} \cdot T_{t}}{(1+d)^{t}}}
$$

$I_{t}$ - nakłady inwestycyjne w poszczególnych latach okresu obliczeniowego;

$K U_{t}$ - koszty utrzymania i remontów w roku $t$;

$k_{p t}$ - koszt paliwa zużytego na wytworzenie jednostki energii;

$P_{t} T_{t}=A_{t}-$ ilość energii elektrycznej wyprodukowana w roku $t$;

$D$ - stopa dyskonta;

$P_{t}-$ moc zainstalowana elektrowni w roku $t$;

$T_{t}$ - czas wykorzystania mocy zainstalowanej w roku $t$.

Przy założeniu stałej mocy zainstalowanej $\mathrm{P}_{\mathrm{t}}=\mathrm{P}$ otrzymuje się (Paska 2012, s. 24-28):

$$
k_{j}=\frac{I_{0}+\sum_{t=1}^{N} \frac{K U_{t}+A_{t} \cdot k_{p t}}{(1+d)^{t}}}{P \cdot T_{i}}
$$

Gdzie:

$T_{i}$-zdyskontowany sumaryczny czas wykorzystania mocy zainstalowanej.

W obliczeniach przyjmuje się wartość wyprodukowanej energii po uwzględnieniu zużycia na potrzeby własne elektrowni.

\section{Metoda $C O E$}

Zbliżony do opisanego powyżej sposób wyznaczania jednostkowego równoważnego kosztu produkcji energii elektrycznej lub ciepła można znaleźć w opracowaniu Komisji Europejskiej Energy Sources, Production Costs and Performance of Technologies for Power Generation, Heating and Transport (EU Commission 2008):

$$
\begin{gathered}
C O E=\frac{S C I \cdot(1+I D C) \cdot C R F}{8760 \cdot L F}+\frac{F O M}{8760 \cdot L F}+V O M+F C+C C+C T S \\
C O H=\frac{S C I \cdot C R F}{876 \cdot L F}+\frac{F O M}{8760 \cdot L F}+V O M+F C \\
I D C=\sum_{k=1}^{C T} W_{k}(1+r) C T-(k-1)-1 \\
C R F=\frac{d(1+d)^{n}}{(1+d)^{n}-1}
\end{gathered}
$$

Gdzie:

$C O E$ - jednostkowy równoważny koszt wytwarzania energii elektrycznej, w euro/(MW $\times \mathrm{h})$;

$\mathrm{COH}$ - jednostkowy równoważny koszt wytwarzania ciepła, w euro/toe; 
$S C I$ - jednostkowe nakłady inwestycyjne na obiekt wytwórczy, w euro/MW lub w euro/toe;

$I D C$ - oprocentowanie nakładów inwestycyjnych w czasie budowy obiektu;

$C R F$ - rata kapitałowa (stopa zwrotu kapitału) the capital recovery factor;

$L F$ - roczny stopień wykorzystania zdolności wytwórczej obiektu;

FOM - równoważne roczne stałe koszty eksploatacyjne, w euro/MW lub

w euro/toe;

$V O M$ - równoważne jednostkowe koszty eksploatacyjne zmienne, w euro/(MW $\times \mathrm{h})$

lub w euro/toe;

$F C$ - równoważne jednostkowe koszty paliwa, w euro/(MW $\times$ h) lub w euro/toe;

$C C$ - równoważne jednostkowe koszty emisji $\mathrm{CO}_{2}$, w euro/(MW $\left.\times \mathrm{h}\right)$;

$C T S$ - równoważne jednostkowe koszty transportu i składowania wychwyconego

$\mathrm{CO}_{2}$, w euro/(MW $\left.\times \mathrm{h}\right)$;

$C T$ - czas budowy obiektu;

$W_{k}$ - względne nakłady inwestycyjne poniesione w roku $k$;

$r$ - stopa oprocentowania;

$d$ - realna stopa dyskonta;

$n$ - czas życia obiektu.

W analizach ekonomicznych najczęściej przyjmuje się dla większości technologii $\mathrm{LF}=0,85$. W przypadku odnawialnych źródeł energii wartość parametru jest inna. Dla systemów fotowoltaicznych wynosi 0,11 , heliotermicznych 0,41 , elektrowni wiatrowych on-shore 0,23 i off-shore 0,39 , dużych elektrowni wodnych 0,5 , małych elektrowni wodnych 0,57 . Równoważne stałe koszty operacyjne FOM uwzględniają koszty utrzymania obiektu, w tym koszty remontów oraz koszty wynagrodzeń. Równoważne koszty eksploatacyjne $V O M$ obejmują materiały eksploatacyjne, koszty użytkowania środowiska, a także energię zużytą na potrzeby własne.

\section{Metoda $L C O E$ i $L A C E$}

Najczęściej stosowaną na świecie metodologią służącą do porównania kosztów wytwarzania energii z różnych źródeł są wskaźniki LCOE i LACE, stosowane przez agencję rządową U.S. Energy Information Administration (EIA 2013). Wskaźnik LCOE stosuje się również w cyklicznej, odbywanej co 5 lat, analizie kosztów wytwarzania energii elektrycznej w krajach OECD dla IEA/NEA. Ostatnie badanie pochodzi z roku 2015 (IEA/NEA 2015). Uśredniony równoważny koszt jednostkowy wytwarzania energii elektrycznej (Levelized Cost of Electricity - LCOE) jest minimalną ceną, przy której suma zdyskontowanych przychodów jest równa sumie zdyskontowanych kosztów, przy uwzględnieniu kosztów poniesionych na budowę i eksploatację oraz finansowych, w szczególności kosztu kapitału własnego, w danym okresie (zazwyczaj życia jednostki).

$$
L C O E=\frac{\sum_{t=1}^{n} \frac{I_{t}+O M_{t}+F_{t}+C_{t}+D_{t}}{(1+d)^{t}}}{\sum_{t=1}^{n} E_{t}(1+d)^{-t}}
$$

Gdzie:

$L C O E$ - równoważny jednostkowy koszt wytwarzania; 
$I_{t}-$ nakłady inwestycyjne w roku $t$;

$O M_{t}-$ wydatki na utrzymanie i remonty w roku $t$;

$F_{t}$ - koszty paliwowe w roku $t$;

$C_{t}$ - koszty emisji $\mathrm{CO}_{2}$ w roku $t$;

$D_{t}-$ koszty likwidacji elektrowni w roku $t$;

$E_{t}$ - wielkość wytworzonej energii elektrycznej w roku $t$

$d$ - stopa dyskontowa;

$n$ - czas życia obiektu.

LCOE może być użytecznym narzędziem w projektowaniu systemu energetycznego i porównywaniu kosztów wytwarzania energii z różnych źródeł. W obliczeniach $L C O E$ przeprowadzonych dla IEA/NEA w 2015 roku zastosowano trzy stopy dyskontowe (3\%, 7\% i 10\%). Badanie opierało się na danych z 22 krajów, z których 19 to kraje OECD, pozostałe 3 to Chiny, Korea Południowa i RPA. Na Rysunku 1 przedstawiono wyniki badań dla technologii konwencjonalnych (IEA/NEA 2015).

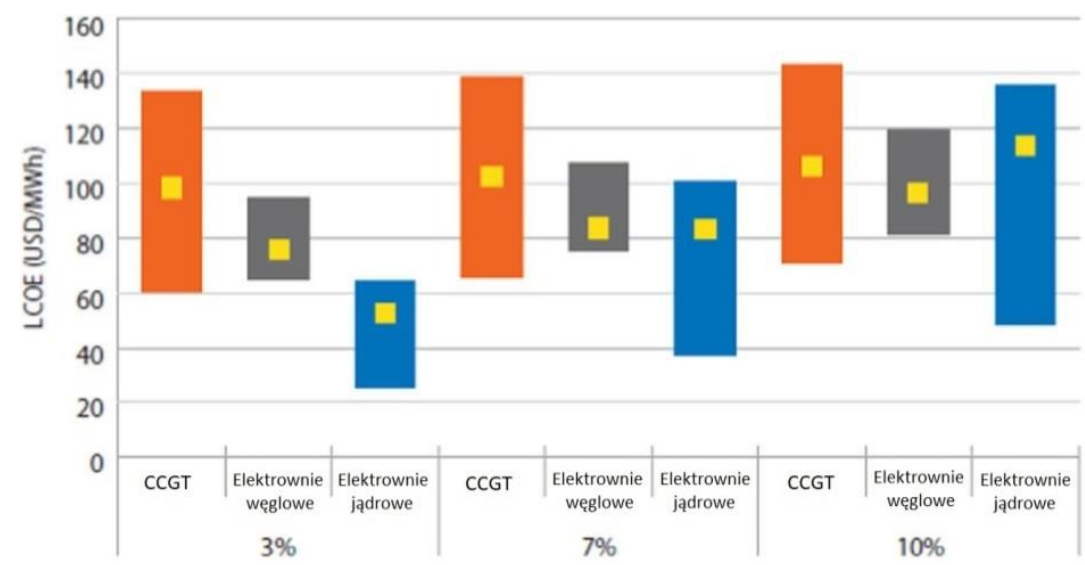

Rysunek 1. Wartość $L C O E$ dla technologii konwencjonalnych (CCGT - układ gazowo-parowy $\mathbf{z}$ turbiną gazową)

Źródło: (IEA/NEA 2015)

W energetyce konwencjonalnej wskaźnik LCOE jest zdeterminowany przez koszty paliwa i koszty kapitałowe, takie jak koszty budowy lub instalacji zakładu produkującego energię, koszty przyłączenia do sieci, koszty pracy. Energetyka odnawialna wymaga natomiast dużych kosztów inwestycyjnych, wynikających m.in. ze stopnia skomplikowania technologii. Zatem koszty O\&M (Operating and Maintenance, czyli operacyjne i utrzymania) w tych technologiach są stosunkowo niewielkie, a o wielkości wskaźnika $L C O E$ decydują głównie koszty finansowe i koszty kapitałowe. Wskaźnik $L C O E$ ma wiele ograniczeń. Nie uwzględnia czynników środowiskowych, społecznych czy też kosztu systemu, tj. długoterminowych implikacji wprowadzenia technologii do systemu pod względem jego kosztów i bezpieczeństwa (Khatib 2016, s. 229-223). Wskaźnik LCOE jest również wrażliwy na subsydiowanie energetyki. Subsydia w sektorze wytwarzania energii proliferują $\mathrm{w}$ danym 
kraju w różnym stopniu, w zależności od prowadzonej polityki energetycznej. Dotacje $\mathrm{w}$ obszarze produkcji energii są najbardziej istotne w przypadku energetyki węglowej, odnawialnej i jądrowej (Difiglio i in. 2015). Przybierają wiele form, zarówno bezpośrednich, jak i regulacyjnych. Ignorowanie wielkości subsydiów zniekształca właściwości informacyjne LCOE. Stąd pojawiające się ogromne różnice w kosztach energii elektrycznej wytwarzanej w obrębie danej technologii w różnych krajach. Jak już wspomniano, w obliczeniach $L C O E$ przeprowadzonych dla IEA/NEA w 2015 roku zastosowano wspólną stopę dyskontową, która odnosi się do różnych technologii generowania energii i decyzji inwestycyjnych. Jednak aspekt wyboru dostosowanej do rodzaju technologii stopy dyskontowej jest niezwykle istotny. Ryzyko inwestowania w obiekty jądrowe lub energetykę odnawialną zdecydowanie różni się od inwestycji w CCGT czy też w tradycyjną energetykę węglową (Khatib 2014). Różne technologie wytwarzania niosą wielorakie zagrożenia. W obliczeniach porównujących koszty różnych technologii wytwarzania można posiłkować się metodologią CAPM, która może prowadzić do odmiennego naliczenia stopy dyskontowej dla każdej technologii. Odpowiednio dostosowana stopa dyskonta, inna dla każdej formy technologii wytwarzania, powinna uwzględniać różnorodność ryzyka generowanego przez daną technologię (Khatib 2016, s. 229-223). Literatura przedmiotu wskazuje wiele metod estymacji LCOE. Branker, Pathak i in. (Branker, Pathak, Pearce 2011, s. 4470-4482) w odniesieniu do technologii solarnej oraz Short, Packey i in. (Short, Packey, Holt 1995) dla energetyki odnawialnej uwzględniają w swoich badaniach różne opcje dyskontowania. Metodologię szacowania $L C O E \mathrm{z}$ zastosowaniem symulacji Monte Carlo (MCS) w swoich badaniach stosują: Darling, You, Veselka i Velosa (Darling i in. 2011, s. 3133-3139) dla energetyki solarnej, Feretic i Tomsic (Feretic, Tomcis 2005, s. 5-13) oraz Roques, Nuttall, Newbery (Roques, Nuttall, Newbery 2006) dla energetyki jądrowej, węglowej i gazowej, Heck, Smith i Hittinger (Heck, Smith, Hittinger 2016, s. 21-30) dla energetyki jądrowej, węglowej, gazowej i odnawialnej oraz Geissmann (Geissmann, Ponta 2017, s. 372-381) w odniesieniu do technologii jądrowej. Autorzy poruszają kwestie wrażliwości obliczeniowej $L C O E$ poprzez uwzględnienie niepewności w zmiennych wejściowych i występujących potencjalnych endogeniczności poprzez symulowanie szeregu alternatyw przy użyciu metody MCS. Natomiast Hogue (Hogue 2012) w odniesieniu do energetyki jądrowej, węglowej i gazowej, Ahmad i Ramana (Ahmad, Ramana 2014, s. 682-694) w odniesieniu do energetyki jądrowej, gazowej i solarnej oraz Heck, Smith i Hittinger (Heck, Smith, Hittinger 2016, s. 21-30) w odniesieniu do energetyki jądrowej, węglowej, gazowej oraz odnawialnej podkreślają w obliczeniach znaczenie kosztów zewnętrznych.

Drugim szeroko wykorzystywanym wskaźnikiem jest $L A C E$. Narzędzie to odzwierciedla koszt, jaki musiałby zostać poniesiony, aby dostarczyć do sieci elektrycznej taką samą moc jak moc analizowanej nowej inwestycji, gdyby moc tej inwestycji nie została dodana do sieci. $L A C E$, podobnie jak $L C O E$, wyrażony jest najczęściej $\mathrm{w}$ dolarach amerykańskich na jednostkę - megawatogodzinę (dol./MWh). Porównując wskaźniki $L C O E$ i $L A C E$, uzyskuje się tzw. wartość netto (net value $-\mathrm{NV}$ ): 
$\mathrm{NV}$ określa potencjalny zysk z inwestycji w przeliczeniu na jednostkę, np. MWh. Jeżeli NV jest większa od zera, to nowa inwestycja jest uważana za opłacalną ekonomicznie. Na Rysunku 2 przedstawiono wartości $L C O E$ i $L A C E$ opracowane dla National Energy Modeling System (NEMS) w kontekście rocznej prognozy energetycznej dla USA (AEO 2017) dla jednostek, których wprowadzenie do użytku planowane jest w 2022 roku.

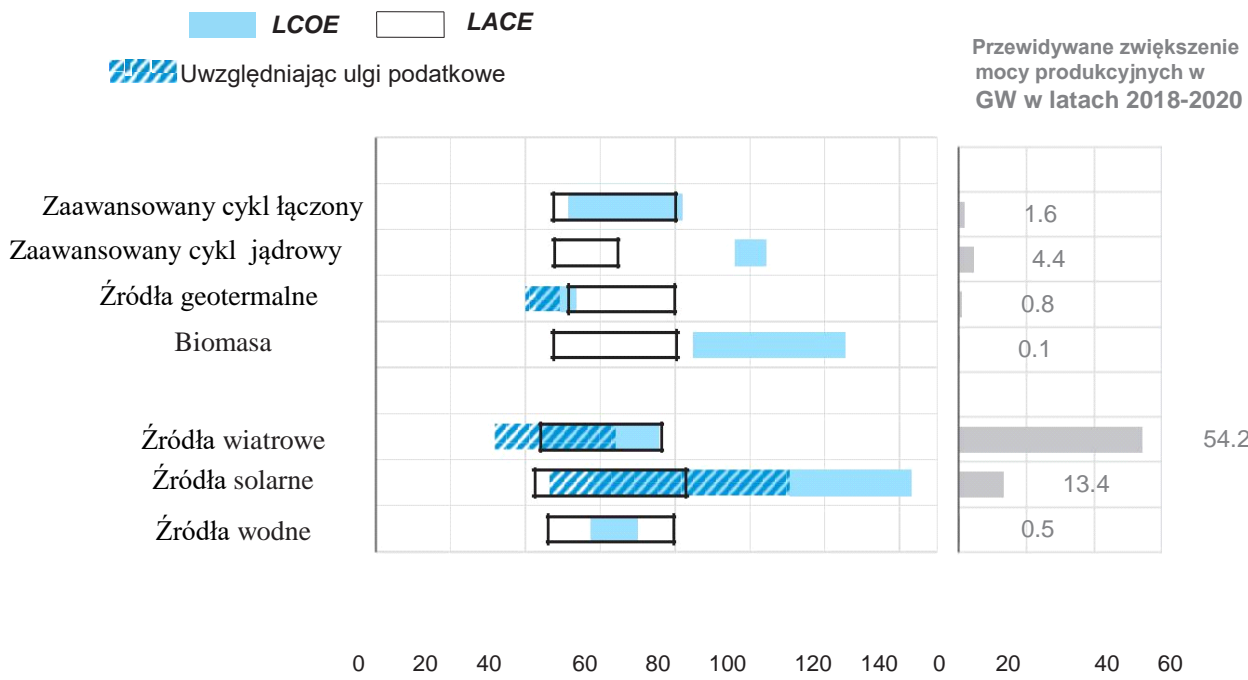

Rysunek 2. $L C O E$ i $L A C E$ dla jednostek, których wprowadzenie do użytku planowane jest w 2022 roku

Źródło: (EIA 2017)

Dodatnia różnica wskazuje, że nowa jednostka może przynosić wartość przekraczającą jej koszt, tym samym zastępując droższe możliwości wytwarzania energii.

\section{Podsumowanie}

Wiedza o wielkości kosztów produkcji energii elektrycznej jest podstawą oceny energetycznych projektów inwestycyjnych. Zwiększa świadomość o potencjalnych dodatnich i ujemnych aspektach wytwarzania energii za pomocą różnych technologii. Ułatwia wybór priorytetów odnośnie sposobu działania i ocenę ewentualnych korzyści. Skwantyfikowanie kosztów, w tym szczególnie kosztów zewnętrznych, odgrywa ważną rolę w procesie wyboru przyszłych technologii energetycznych oraz jest pomocne przy ustalaniu polityki fiskalnej, na przykład rodzajów i wielkości podatków ekologicznych. Wytwarzanie energii elektrycznej związane jest bowiem z 
trudnym do skwantyfikowania szeregiem ujemnych oddziaływań na środowisko naturalne, wśród których do najważniejszych można zaliczyć: zanieczy-szczenie powietrza atmosferycznego, wód powierzchniowych i gleby oraz globalne zmiany klimatu. Koszty wywoływanych w ten sposób szkód zwykle nie są odpowiednio odzwierciedlane w rynkowej cenie energii. Prawidłowe i pełne określenie kosztów zewnętrznych technologii energetycznej wymaga analizy cyklu całego życia i systemu wytwarzania. W przypadku technologii wytwarzania energii elektrycznej skutki zewnętrzne mogą występować w wielu fazach cyklu paliwowego.

Celem artykułu była analiza porównawcza, ustalenie zależności, pokrewieństw, analogii pomiędzy metodologią szacowania kosztów wytwarzania energii elektrycznej stosowaną w Unii Europejskiej i USA. Przedstawione metody analizy kosztów produkcji energii elektrycznej różnią się mimo pewnych wspólnych założeń, takich jak: analiza kosztów w całym cyklu życia elektrowni, wykorzystanie w obliczeniach rachunku dyskontowego itp. Stosując $w$ analizach ekonomicznych różnorodne mierniki kosztów, w tym wskaźniki $L C O E$ i $L A C E$, trzeba uwzględnić szereg czynników, które są bardzo zmienne w zależności od czasu i miejsca lokalizacji inwestycji energetycznej. Wymagają wiedzy na temat kosztów budowy i eksploatacji, kosztów finansowania, kosztów dostępu do źródeł paliwa, transportu, utylizacji i szeregu innych. Nie uwzględniają najczęściej również tzw. kosztów zewnętrznych, czyli np. kosztów środowiskowych czy też kosztów generowanych przez energetykę w opiece zdrowotnej, co może prowadzić do całkowicie mylnych wniosków, różnych interpretacji, a w konsekwencji do błędnych decyzji inwestycyjnych. Wiarygodna i pełna analiza kosztów produkcji energii elektrycznej powinna być brana pod uwagę przy określaniu polityki ekologicznej i energetycznej państwa oraz w procesie decyzyjnym, jeśli celem jest optymalne wykorzystywanie zasobów oraz zapewnienie największych korzyści dla społeczeństwa.

\section{Literatura}

1. AEO (2017), Annual Energy Outlook 2017, January 2, 2017, https://www.eia.gov/ pressroom/presentations/sieminski_01052017.pdf (dostęp: 21.03.2017).

2. Ahmad A., Ramana M.V. (2014), Too Costly to Matter: Economics of Nuclear Power for Saudi Arabia, „Energy”, Vol. 69, Issue C, May, s. 682-694. DOI: 0.1016/j.energy. 2014.03.064

3. Branker K., Pathak M.J.M., Pearce J.M. (2011), A Review of Solar Photovoltaic Levelized Cost of Electricity, „Renew Sustain Energy Reviews”, Vol. 15(9), s. 4470-4482. DOI: 10.1016/j.rser.2011.07.104

4. Darling S.B., You F., Veselka T., Velosa A. (2011), Assumptions and the Levelized Cost of Energy for Photovoltaics, „Energy \& Environmental Science”, Vol. 4(9), s. 3133-3139. DOI: 10.1039/c0ee00698j

5. Difiglio C., Budnitz R., Jefferson M., Khatib H., Masuda T., McCombie C.H., Ongena J., Pierpoint L., Shihab-Eldin A., Stram B. (2015), Renewable and Nuclear Electricity: Opportunities, Challenges and Policy Recommendations, World Federation of Scientists Annual Meeting, Prepared for the 2015 Erice Seminars, 18 July, 2015.

6. EIA (2013), Levelized Cost of Electricity and Levelized Avoided Cost of Electricity Methodology Supplement, U.S. Energy Information Administration, July 2013. 
7. EIA (2017), Energy Information Administration, Levelized Cost and Levelized Avoided Cost of New Generation Resources in the Annual Energy Outlook 2017, U.S. Energy Information Administration, April 2017.

8. EU Commission (2008), Energy Sources, Production Costs and Performance of Technologies for Power Generation, Heating and Transport, COM (2008) 744.

9. EU Commission (2016), Report from the Commission to the European Parliament, the Council, the European Economic and Social Committee and the Committee of the Regions. Energy Prices and Costs in Europe, SWD (2016) 420 final, European Commission, Brussels.

10. Feretic D., Tomsic Z. (2005), Probabilistic Analysis of Electrical Energy Costs Comparing: Production Costs for Gas, Coal and Nuclear Power Plants, „Energy Policy”, Vol. 33(1), s. 5-13. DOI: 10.1016/S0301-4215(03)00184-8

11. Frydrychowicz-Jastrzębska G., Bugała A. (2014), The UNIPEDE Method of Assessing Electric Energy Generation Costs in Photovoltaic Systems, „Przegląd Elektrotechniczny”, R. 90, nr 12, s. 68-71. DOI: 10.12915/pe.2014.12.15

12. Geissmann T., Ponta O. (2017), A Probabilistic Approach to the Computation of the Levelized Cost of Electricity, „Energy”, Vol. 124, s. 372-381. DOI: 10.1016/j.energy.2017. 02.078

13. Heck N., Smith C., Hittinger E. (2016), A Monte Carlo Approach to Integrating Uncer-tainty into the Levelized Cost of Electricity, „The Electricity Journal”, Vol. 29(3), s. 21-30. DOI: 10.1016/j.tej.2016.04.001

14. Hogue M.T. (2012), A Review of the Costs of Nuclear Power Generation, Bureau of Economic and Business Research (BEBR), David Eccles School of Business, University of Utah, Salt Lake City.

15. IEA/NEA (2015), Projected Costs of Generating Electricity. International Energy Agency (IEA) and Nuclear Energy Agency (NEA), 2015 Edition, Paris, France.

16. Khatib H. (2014), Economic Evaluation of Projects in the Electricity Supply Industry, 3rd Edition, The Institution of Engineering and Technology, London.

17. Khatib H. (2016), A Review of the IEA/NEA Projected Costs of Electricity - 2015 Edition, „Energy Policy”, Vol. 88, s. 229-233. DOI: 10.1016/j.enpol.2015.10.030

18. Li Y., Chen D.W., Liu M., Wang R.Z. (2017), Life Cycle Cost and Sensitivity Analysis of Hydrogen System Using Low-Price Electricity in China, „International Journal of Hydrogen Energy", Vol. 42, s. 1899-1911. DOI: 10.1016/j.ijhydene.2016.12.149

19. Paska J. (2012), Metodyka oceny kosztów wytwarzania energii elektrycznej, „Rynek Energii”, nr 2, s. 1-6.

20. Roques F.A., Nuttall W.J., Newbery D.M. (2006), Using Probabilistic Analysis to Value Power Generation Investments under Uncertainty, University of Cambridge, Faculty of Economics, Cambridge.

21. Short W., Packey D.J., Holt T. (1995), A Manual for the Economic Evaluation of Energy Efficiency and Renewable Energy Technologies, National Renewable Energy Laboratory, Golden.

22. WCED Brundtland Commission (1987), Our Common Future, Report of the World Commission on Environment and Development Oxford University Press, Oxford. 


\title{
COMPARISON OF METHODS FOR ESTIMATING COSTS OF ELECTRICITY GENERATION
}

\begin{abstract}
The methodology of analysis of electricity generation costs should take into account the whole life cycle of the power plant, including the time of building, exploitation and eventually costs connected with object disposal. The costs should cover total investment expenses and running costs together with environmental costs. Their values should be brought to a common moment of time using discounting calculus. The aim of the article is a comparative analysis, establishing dependence, kinship, analogy between the methodology for estimating the costs of electricity production used in the European Union and the US.
\end{abstract}

Keywords: electrical energy, production costs, unitary discount electricity generation cost 